9 Douglas JG, Gillon J, Logan RF, et al. Sarcoidosis and coeliac disease: an association? Lancet 1984;2:13-15.

10 Anon. Sarcoidosis and coeliac disease. Lancet 1984;2:408.

11 Lowe G, Johnston RN. Sarcoidosis and coeliac disease. Lancet 1984;2:637.

12 Rutherford RM, Brutsche MH, Kearns $M$, et al. Prevalence of coeliac disease in patients with sarcoidosis. Eur J Gastroenterol Hepatol 2004;16:911-15.

13 Zasloff M. Fighting infections with vitamin D. Nat Med 2006; 12:388-96.

14 Rockett KA, Brookes R, Udalova I, et al. 1,25Dihydroxyvitamin D3 induces nitric oxide synthase and suppresses growth of Mycobacterium tuberculosis in a human macrophage-like cell line. Infect Immun, 1998 Nov, 66:5314-21.
15 Correa PA, Gomez LM, Cadena J, et al. Autoimmunity and tuberculosis. Opposite association with TNF polymorphisms. J Rheumatol 2005;32:219-24.

16 Schorey JS, Carroll MC, Brown EJ. A macrophage invasion mechanism of pathogenic mycobacteria. Science 1997;277:1091-3.

17 Shetty A, McKendrick M. TB and coeliac disease. $J$ Infect 2004:48:109-11.

\title{
High-grade lesion: what does it tell us?
}

\section{E S Edell}

\section{Surveillance programmes for patients with high-grade lesions, which may progress to invasive cancer, will require tissue archives for histology and cooperation and collaboration of participating centres}

L ung cancer remains the leading cause of death due to cancer in both men -and women in several countries. Most patients with lung cancer present with non-specific symptoms such as cough, dyspnoea or haemoptysis and have latestage disease at the time of diagnosis. Treatment strategies are thus often palliative rather than curative. Early detection trials using routine chest roentgenograms and sputum cytology have shown that cancers can be detected at earlier stages but the overall mortality from lung cancer was not improved. With new technology developments, such as low-dose computed tomography and fluorescence bronchoscopy, comes new hope that early detection may in fact change this pattern.

Squamous cell carcinoma, although no longer the most common type of lung cancer, remains a major problem, accounting for $17-29 \%$ of lung cancers. ${ }^{1}$ Studies on sputum cytology showed that $11 \%$ of individuals with moderate dysplasia and 19-46\% with severe dysplasia progressed to squamous cell cancers. Once detected, localisation of these early lesions was not easy using conventional white-light bronchoscopy. Thus, fluorescence bronchoscopy systems were developed to improve the detection of preinvasive and invasive lesions of the central airways. Several studies showed the improved detection of both preinvasive and invasive cancers using fluorescence bronchoscopy compared with white-light bronchoscopy alone. ${ }^{2-5}$ As often happens, however, many new questions have surfaced as more patients are found to have these preinvasive lesions.
For example, what should be done with a patient who has an abnormal area showing carcinoma in situ on a biopsy specimen? Several studies have suggested that the carcinoma in situ, if left alone, will progress to invasive cancer and should be treated. ${ }^{67}$ What about a patient with severe dysplasia? Here the data suggest that the rate of progression to invasive cancer is much less but sufficiently high for these patients to be followed-up. ${ }^{8}$ But do we really know the natural history of these lesions?

In this issue of Thorax, George et al ${ }^{10}$ (see $p$ 43) have presented their work on 22 patients with either previous lung cancer, asbestos exposure or known chronic obstructive pulmonary disease. Fifty one lesions were identified using fluorescence bronchoscopy. High-grade lesions included seven classified as severe dysplasia, 28 as carcinoma in situ and 16 as low-grade lesions of mild or moderate dysplasia. These patients were followed up for a median of 23 months (range 1285 months). Indolence or regression was observed in $83 \%$ of the high-grade lesions and no progression was seen in any of the low-grade lesions. However, five patients with high-grade lesions subsequently developed cancers that were detected by computed tomography during their follow-up.

What can be learned from the work by George et al? ${ }^{10}$ Their data do not change the current practice that patients with carcinoma in situ should receive treatment. Surgical resection remains the standard treatment, but local treatment such as photodynamic therapy or argon plasma coagulation could be an option if carried out in a clinical trial. ${ }^{11}$ For patients who are not surgical candidates either because of poor pulmonary function or other comorbidities, local treatment has been shown to be a reasonable option. ${ }^{12-14}$ What about those patients with severe dysplasia? The experience presented by George et al ${ }^{10}$ shows that these patients are at high risk for developing an invasive cancer. In this population, surveillance is important with both fluorescence bronchoscopy and with computed tomography of the chest.

As we look to the future many gaps remain in our understanding of the natural history of squamous cell carcinoma, and lung cancer in general. Studies such as the one by George et $a l^{10}$ have again shown that there are subsets of patients with high-grade lesions that progress to invasive cancers and others that do not. This shows the need for reliable markers in tumour biology. George et $a l^{10}$ point out that surveillance programmes need to include tissue archives of blood, sputum and bronchial specimens, thus enabling studies on histologically identical lesions with different clinical outcomes. This work will require the cooperation and collaboration of many centres involved in surveillance programmes.

Thorax 2007:62:2-3.

doi: 10.1136/thx.2006.067876

Correspondence to: Dr E S Edell, Mayo Clinic, First Avenue SW, Rochester, MN 55902, USA; eedell@mayo.edu

Competing interests: None declared.

\section{REFERENCES}

1 Greenlee RT, Hill-Harmon MB, Murray T, et al. Cancer Statistics, 2001. CA Cancer J Clin 2001;51:15-36.

2 Venmans BJW, van Boxem AJM, Smit EF, et al. Early detection of preinvasive lesions in high-risk patients. A comparison of conventional flexible and fluorescence bronchoscopy. J Bronchol 1998;5:280-3.

3 Horvath T, Horvathova M, Salaika F, et al. Detection of bronchial neoplasia in uranium miners by autofluorescence bronchoscopy. Diagn Ther Endosc 1999:5:91-8.

4 Shibuya K, Fujisawa $\mathrm{T}$, Hoshino $\mathrm{H}$, et al. Fluorescence bronchoscopy in the detection of preinvasive bronchial lesions in patients with sputum cytology suspicious or positive for malignancy. Lung Cancer 2001;32:19-25.

5 Ikeda N, Hiyoshi T, Kakihana M, et al. Histopathological evalutation of fluorescence 


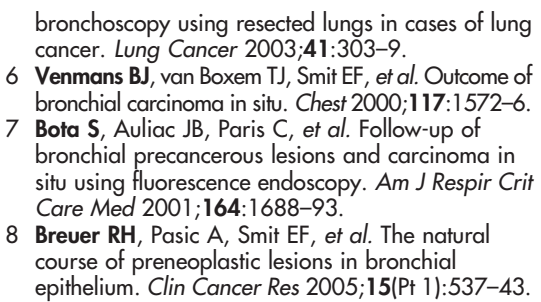

bronchoscopy using resected lungs in cases of lung cancer. Lung Cancer 2003:41:303-9.

6 Venmans BJ, van Boxem TJ, Smit EF, et al. Outcome of bronchial carcinoma in situ. Chest 2000;1 17:1572-6.

7 Bota S, Auliac JB, Paris C, et al. Follow-up of bronchial precancerous lesions and carcinoma in situ using fluorescence endoscopy. Am J Respir Crit Care Med 2001; 164:1688-93.

8 Brever RH, Pasic A, Smit EF, et al. The natural course of preneoplastic lesions in bronchial epithelium. Clin Cancer Res 2005;15(Pt 1):537-43.

9 Lam S, Slivinskas J, McWilliams A, et al. Natural history of premalignant bronchial lesions: implications for chemoprevention. Am Assoc Cancer Res 2002.

10 George PJ, Banerjee AK, Read CA, et al. Surveillance for the detection of early lung cancer in patients with bronchial dysplasia. Thorax 2005;62:43-50.

11 Cortese DA, Edell ES, Kinsey J. Photodynamic therapy for early stage squamous cell carcinoma of the lung. Mayo Clin Proc 1997;72:595-602.
12 Edell ES, Cortese DA. Bronchoscopic phototherapy with hematoporphyrin derivative for treatment of localized bronchogenic carcinoma: a 5 -year experience. Mayo Clin Proc 1987:62:8-14

13 Kato H. Photodynamic therapy for lung cancer of-a review of 19 years experience. J Photchem Photobiol 1998:42:96-9.

14 Mathur PN, Edell ES, Sutedja T, et al. Treatment of early stage non-small cell lung cancer. Chest 2003;123:S176-80.

\section{What is this thing called CFA?}

\section{A U Wells, D M Hansell, A G Nicholson}

\section{The term "cryptogenic fibrosing alveolitis"should now be used as strictly synonymous with "idiopathic pulmonary fibrosis"}

\footnotetext{
A rcane diagnostic labels bother clinicians. The diffuse lung disease lexicon is a notorious example. For decades, "diffuse lung disease speak" consisted of an unholy mix of histopathological and clinical terms, varying between countries, within countries and even between medical teams in the same hospital. Radical change was required and proposals were advanced in a joint American Thoracic Society and European Respiratory Society (ATS/ERS) initiative. Terminology for idiopathic interstitial pneumonia was distilled by a core group of clinicians, radiologists and pathologists, and this was then circulated to a larger group of international reviewers and published in 2002. ${ }^{1}$ The final consensus classification was not, at first sight, straightforward to apply. Indeed, the amorphous entity of "non-specific interstitial pneumonia" (NSIP) continues to vex clinicians and requires further subclassification. However, teething problems aside, the ATS/ERS initiative has been an outstanding success. Clinicians and researchers worldwide now understand each other better than before. The recent move towards large multicentre treatment studies in idiopathic pulmonary fibrosis (IPF), itself a revolution in slow motion, was made possible, in no small part, by this standardisation of terminology and disease definitions.

As the terminology has changed, the article by Rudd et $a l^{2}$ in the current issue of Thorax (see $p$ 67) is likely to pose difficulties for some non-UK readers. The authors have studied "cryptogenic fibrosing alveolitis" (CFA) as a clinical presentation, as used historically in the UK. The diagnostic criteria, consisting of
}

compatible radiographic, pulmonary function and clinical findings, in the absence of an overt environmental or autoimmune cause, are highly non-specific: compatible, also, with idiopathic interstitial pneumonias other than IPF and a subgroup of patients with hypersensitivity pneumonitis. By contrast, in the ATS/ERS classification, ${ }^{13}$ CFA is explicitly synonymous with IPF, as defined at biopsy or using high resolution computed tomography (HRCT) criteria, with typical clinical features also required, and this is now accepted internationally. Rudd et $a l^{2}$ discuss this issue in their methods section. However, their definition of CFA, as corresponding to "idiopathic pulmonary fibrosis in US terminology", is no longer correct using the current classification and, in reality, was probably never correct. In historical US series, the diagnosis of IPF was wholly or largely based on histopathological data; the application of ATS criteria essentially involved reclassifying NSIP cases and a small number of other disorders. ${ }^{4}$ By contrast, the historical UK entity of CFA was diagnosed at surgical biopsy in only $12 \%$ of cases in the early 1990s, ${ }^{5}$ and a large number of disorders other than IPF were necessarily included. Thus, the current British Thoracic Society (BTS) study is nothing more or less than a study of a non-specific clinical presentation, and unless this is understood, the findings will be misinterpreted.

The presence of two very different entities in the current medical literature, both termed CFA, cannot be a good thing. However, in their use of historical terminology, Rudd et al ${ }^{2}$ perhaps imply that something nosologically important has been lost. The concept of a "CFA" presentation is undoubtedly useful. The typical clinical picture is readily recognised in the outpatient clinic, even before tests such as HRCT. A "CFA" presentation is a key starting point in the personal diagnostic algorithms of many experienced clinicians. Furthermore, knowledge of a clinical picture of "CFA" informs prognostic evaluation. It is increasingly clear that the histological pattern of NSIP is associated with several distinct clinicoradiological entities, with HRCT and clinical findings often those of organising pneumonia with fibrosis ${ }^{6}$ or hypersensitivity pneumonia. ${ }^{7}$ However, the good outcome in these subgroups contrasts with outcomes in patients with idiopathic NSIP with a "CFA" clinical presentation: although prolonged survival is sometimes attainable, a poor IPF-like outcome is equally common, despite aggressive treatment. ${ }^{8}$ A frank admission that the prognosis is uncertain is crucial if therapeutic options are to be discussed with patients in an informed manner.

Perhaps more importantly, a "CFA" presentation has been, and is, indispensable for epidemiological work. It is simply unrealistic to require the application of formal ATS/ERS criteria for IPF, including HRCT, biopsy and bronchoalveolar lavage findings, in studies of the prevalence and spectrum of disease outside referral centres. An inclusive approach is required-in other words, a clinical diagnosis is necessary. Epidemiological work on diffuse lung disease is vital. The track record of public funding bodies (such as the Medical Research Council) in supporting therapeutic studies of diffuse lung disease is poor, partly because of a lingering perception that IPF is an uncommon disease confined to referral centres. Studies to establish the true impact of diffuse lung disease outside specialist units are particularly important in disorders that are strikingly more prevalent with increasing age, but this view was, perhaps, underrepresented in the ATS/ERS deliberations. The redefinition of CFA as synonymous with IPF has effectively disenfranchised epidemiologists, who, it could be argued, now have to study a disorder without a 